\title{
Temperature Dynamics Assessment of Agricultural Objects Based on Unmanned Aircraft Data
}

\author{
Dmitry V. Emelyanov*, Irina Y. Botvich, \\ Nikita O. Malchikov and Anatoly P. Shevyrnogov \\ Institute of Biophysics SB RAS \\ Krasnoyarsk, Russian Federation
}

Received 03.08.2020, received in revised form 21.08.2020, accepted 10.09.2020

\begin{abstract}
During the study, the spatial and temporal distribution of radiant temperature of agricultural fields has been made. The object of the study is agricultural fields (barley, oats, fallow field, perennial grasses (Onobrychis)), located on the territory of the Krasnoyarsk Research Institute of Agriculture of the FRC KSC SB RAS near the village of Minino (Central Siberia, Krasnoyarsk region). The radiant temperature measurement of objects surface was taken by the ZENMUSE XT2 camera installed on the unmanned aircraft DJI Matrice 210 RTK V2. The spatial resolution of the obtained thermal maps is 12 $14 \mathrm{~cm}$. The state of the objects (the presence of vegetation cover) was assessed using the NDVI values obtained from the PlanetScope satellite data with a spatial resolution of 3 meters. It was established that the presence of plants and the size of their projective cover are decisive in the formation of soil cover temperature conditions. The growth and development of the vegetation cover, its height and closeness, change the temperature regime conditions. Instead of a soil, vegetation cover becomes an active surface. The thermal maps (spatial distribution of radiant temperature) of the agricultural land surface has been carried out, which makes it possible to assess the in-field temperature heterogeneity of the objects.
\end{abstract}

Keywords: radiation temperature, agricultural fields, thermal map, ZENMUSE X5S, ZENMUSE XT2.

Citation: Emelyanov D.V., Botvich I.Y., Malchikov N.O., Shevyrnogov A.P. Temperature dynamics assessment of agricultural objects based on unmanned aircraft data, J. Sib. Fed. Univ. Eng. \& Technol., 2020, 13(6), 757-765. DOI: 10.17516/1999-494X0264

(c) Siberian Federal University. All rights reserved

This work is licensed under a Creative Commons Attribution-Non Commercial 4.0 International License (CC BY-NC 4.0).

* Corresponding author E-mail address: dima9526@gmail.com 


\title{
Оценка динамики температур \\ сельскохозяйственных объектов \\ по данным беспилотных воздушных судов
}

\author{
Д.В. Емельянов, И.Ю. Ботвич, \\ Н.О. Мальчиков, А.П. Шевырногов \\ Институт биофизики СО РАН \\ Российская Федеращия, Красноярск
}

Аннотация. В ходе проведенного исследовании выполнена оценка пространственного и временного распределения радиационной температуры сельскохозяйственных угодий. Объектом исследования являются сельскохозяйственные угодья (посев ячменя, посев овса, паровое поле, посев многолетних трав (эспарцет)), расположенные на территории Красноярского НИИСХ ФИЦ КНЦ СО РАН вблизи пос. Минино (Средняя Сибирь, Красноярский край). Измерение радиационной температуры поверхности исследуемых объектов выполнено камерой ZENMUSE XT2, установленной на беспилотном воздушном судне DJI Matrice 210 RTK V2. Пространственное разрешение полученных термокарт составляет 12-14 см. Оценку состояния исследуемых объектов (наличие растительного покрова) проводили по значениям NDVI, полученных по спутниковым данным PlanetScope с пространственным разрешением 3 м. Установлено, что присутствие растений и величина их проективного покрытия являются определяющими в формировании температурных условий почвенного покрова. Рост и развитие растительного покрова, его высота и сомкнутость изменяют условия температурного режима. Деятельной поверхностью становится не почва, а растительный покров. Проведено построение термокарт (пространственного распределения радиационной температуры) поверхности сельскохозяйственных угодий, что позволяет оценивать внутрипольную неоднородность температуры исследуемых объектов.

Ключевые слова: радиационная температура, сельскохозяйственные угодья, термокарта, ZENMUSE X5S, ZENMUSE XT2.

Цитирование: Емельянов, Д.В. Оценка динамики температур сельскохозяйственных объектов по данным беспилотных воздушных судов / Д.В. Емельянов, И.Ю. Ботвич, Н.О. Мальчиков, А.П. Шевырногов // Журн. Сиб. федер. ун-та. Техника и технологии, 2020. 13(6). С. 757-765. DOI: 10.17516/1999-494X-0264

\section{Введение}

Знания о динамике радиационной температуры сельскохозяйственных угодий несут в себе огромный потенциал. Регулярный мониторинг радиационной температуры угодий позволяет получить информацию для оценки состояния сельскохозяйственных посевов.

Информация такого типа дает возможность оценивать индекс засухи, влажность почв, которая может использоваться для планирования орошения, определить процент всхожести посевов, выделить зоны с повышенной и пониженной температурой. Она может быть полезна для оценки состояния всходов, выполнения картирования структуры почв. Регулярно получаемая информация о состоянии радиационной температуры посевов дает возможность выделить этапы созревания зерновых культур, что позволяет определить оптимальное время для его сбора [1-4].

Однако на текущий момент подавляющее количество информации о состоянии температур различных объектов, включая сельскохозяйственные угодья, идет со спутниковых носи- 
телей, которые имеют большой недостаток - низкое пространственное разрешение. Например, спутники серии MODIS TERRA имеют пространственное разрешение в тепловом диапазоне около 1000 м, Landsat-8 - около 100 м. Данные с таким пространственным разрешением применимы на региональном и федеральном уровнях, но не могут дать полноценной картины о состоянии радиационной температуры полей на уровне отдельных хозяйств [5-7].

Поэтому для мониторинга сельскохозяйственных угодий на локальном уровне предложено применять беспилотные воздушные суда (БВС) со специализированным типом полезной нагрузки - тепловизионными камерами. Например, БBC DJI Matrice 210 RTK V2 с полезной нагрузкой в виде тепловизионной камеры Zenmuse XT2 позволяет получать карты радиационной температуры с пространственным разрешением вплоть до 2-3 см и использовать потенциал получаемых данных о состоянии радиационной температуры сельскохозяйственных угодий в полной мере.

Цель исследования - оценка пространственного и временного распределения радиационной температуры сельскохозяйственных угодий.

\section{Материалы и методы исследований}

Объектом исследования являются сельскохозяйственные угодья на территории Красноярского НИИСХ ФИЦ КНЦ СО РАН вблизи пос. Минино (Средняя Сибирь, Красноярский край). Исследования проведены на следующих тестовых участках: посев ячменя, посев овса, паровое поле, посев многолетних трав (эспарцет) (рис. 1). Посев ячменя производили при глубинной обработке почвы. Посев овса выполнен без обработки почвы, в связи с чем отмечено присутствие большого количества стерни на поверхности почвы. Тестовые участки расположены в непосредственной близости друг от друга, что обеспечивает одинаковое влияние метеоусловий на исследуемые объекты.

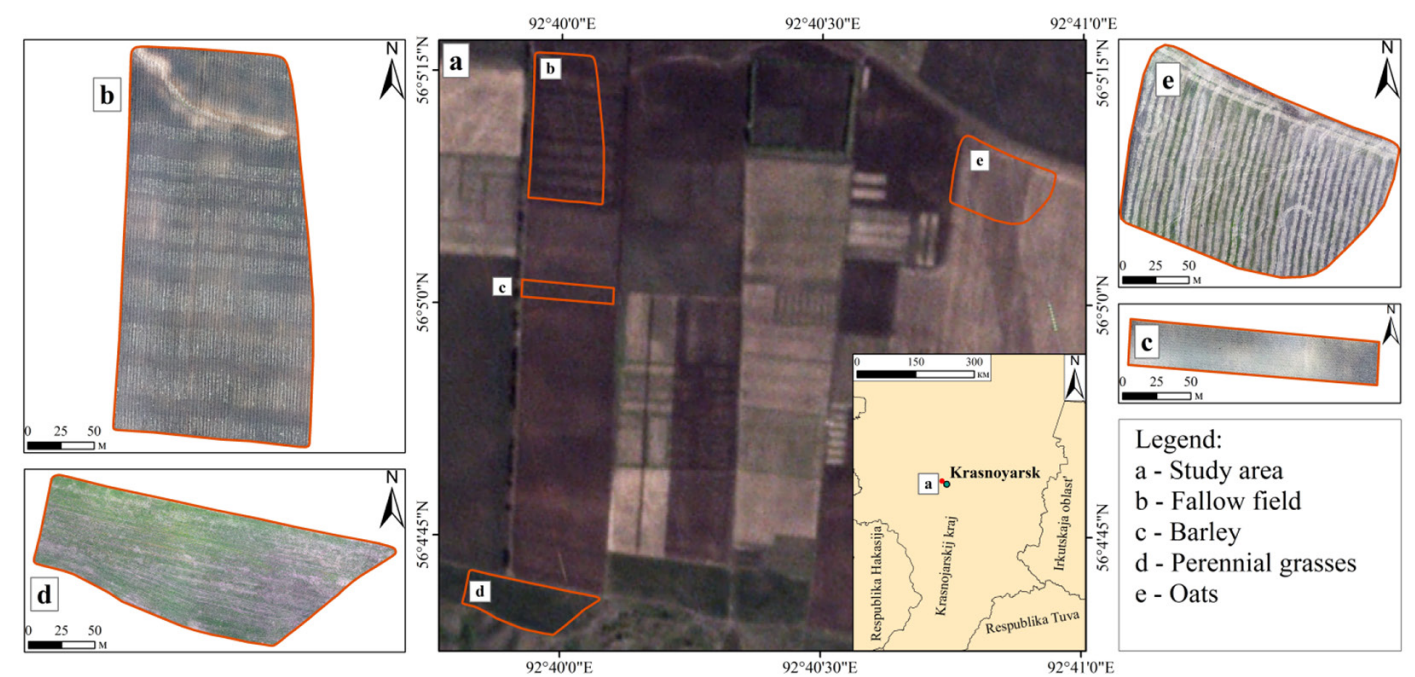

Рис. 1. Карта расположения тестовых участков. В качестве базовой карты использовано изображение, полученное по данным PlanetScope от 24 мая 2020 г.

Fig. 1. The map of study. The basemap is an image from PlanetScope (May 24, 2020) 
Работа основывается на данных с беспилотного воздушного судна DJI Matrice 210 RTK V2 с полезной нагрузкой в виде камер ZENMUSE X5S и ZENMUSE XT2. БВС имеет систему RTK, которая позволяет достигать точности географической привязки до 2 см.

Камера ZENMUSE X5S дает возможность получать цифровые изображения с разрешением $5120 x 2880$ пикселей, что помогает достигать высокой детализации изображения с больших высот. На основе полученных данных произведено построение 3D-модели местности. Это предоставляет такую информацию, как высота объектов (в том числе растений), состояние рельефа и т.д.

Камера ZENMUSE XT позволяет вести съемку в тепловом диапазоне 7.5-13.5 $\mu \mathrm{m}$ с разрешением 640x512 пикселей.

Перед совершением полетов над тестовыми участками был проведен ряд подготовительных мероприятий: получение разрешения на выполнения полетов в Новосибирском зональном центре и главном центре ЕС ОрВД (установление временного режима); рекогносцировка на местности и выбор высоты полета (с целью исключения чрезвычайных ситуаций).

Перед непосредственным запуском БВС и съемкой на местности устанавливали наземную станцию DJID-RTK 2 for Matrice series. Совместная работа данной наземной станции и БВС позволяет получать снимки с точностью координатной привязки равной $1,5-2 \mathrm{~cm}$.

Для выполнения съемки и получения корректных данных использованы специализированные программные средства: DJI Pilot и Pix4DMapper.

Программy DJI Pilot применяли для составления полетного задания. При использовании камеры ZENMUSE X5S в качестве входных параметров выбрано продольное и поперечное перекрытие снимков - 80 и 70 \% соответственно, высота полета - 100 метров от точки взлета, съемка проводилась в надир. Пространственное разрешение полученных изображений составляет $2-4$ см.

При использовании камеры ZENMUSE XT2 в качестве входных параметров выбрано продольное и поперечное перекрытие снимков - 80 и 70 \%, соответственно, высота полета - 100 м

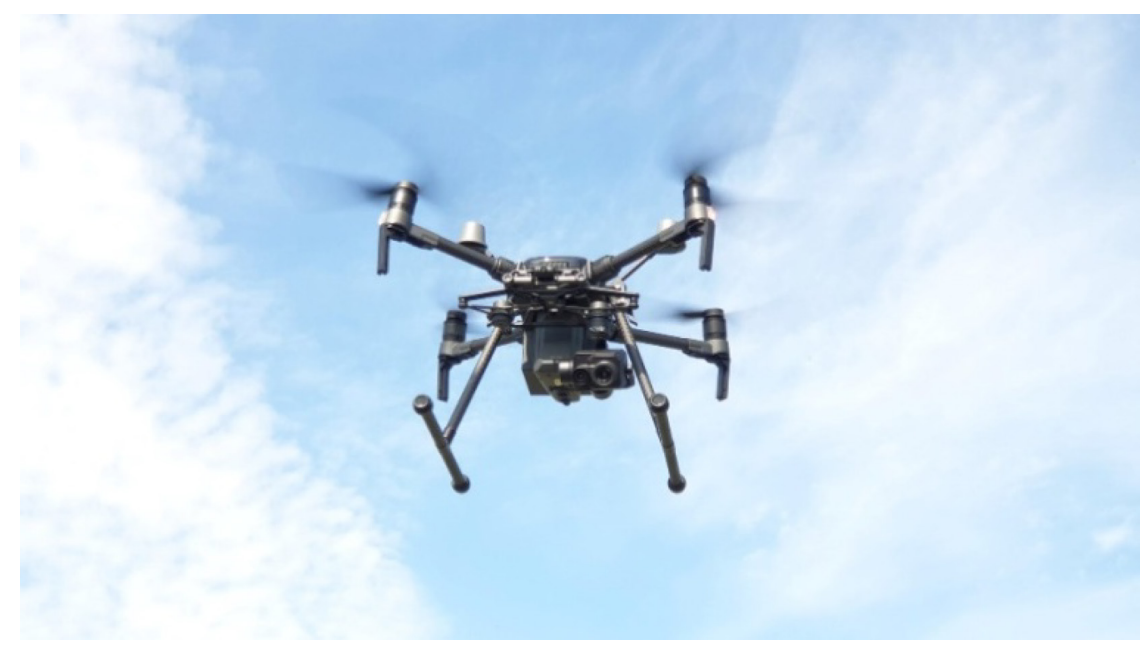

Рис. 2. DJI Marice 210 RTKV2 с полезной нагрузкой в виде камеры ZENMUSE XT2

Fig. 2. DJI Marice 210 RTKV2 with ZENMUSE XT2 camera payload 
от точки взлета, съемка проводилась в надир. Пространственное разрешение полученных изображений составляет 12-14 см.

После завершения всех подготовительных этапов начинали процесс непосредственной съемки, выполнения полетного задания, во время которого были отключены функции автоматической фокусировки камеры и калибровки камеры по температуре во избежание получения искажения изображений (данные процедуры выполняли единожды при наборе рабочей высоты). Радиационную температуру объектов измеряли с 11 до 14 ч местного времени.

Обработку данных, полученных ZENMUSE XT2 и ZENMUSE X5S, выполняли в Pix4DMapper. Данное программное обеспечение позволяет составлять ортофотопланы из различных наборов и типов данных (спектральные, RGB-снимки, снимки с тепловых камер) в автоматическом режиме. Для обработки снимков с камеры Zenmuse XT2 установлен режим «Thermal camera», выполнение которого позволяет получить температурную карту местности.

Оценка состояния исследуемых объектов (наличие растительного покрова) проведена по спутниковым данным PlanetScope с пространственным разрешением 3 м. На этапе предварительной обработки осуществляли атмосферную коррекцию данных PlanetScope. Корректирующие коэффициенты для каждого канала присутствуют в метаданных каждой сцены.

В ходе тематической обработки спутниковой информации производился расчет значений NDVI (Normalized Difference Vegetation Index) [8]. Расчет NDVI базируется на данных красного (RED) и ближнего инфракрасного (NIR) диапазонов оптического спектра:

$$
N D V I=\frac{N I R-R E D}{N I R+R E D}
$$

\section{Результаты исследований}

На лишенных растительного покрова поверхностях горных пород и почв радиационная температура определяется их вещественным составом. Температурные характеристики почв определяются, прежде всего, их цветом, составом и объемной долей минералов в ее составе, размером частиц почвы, содержанием органического вещества, пористостью и влажностью. Наличие на поверхности почвы растительного покрова вносит значительные изменения в температурный режим. Вид растительности, высота, мощность крон и густота растительного покрова определяют то количество солнечной радиации, которое достигает поверхности почвы [9]. Часть падающей на листья солнечной радиации отражается от листовой поверхности и снова уходит в атмосферу, часть - поглощается листьями, расходуется на фотосинтез и в значительной мере на процесс испарения, часть - проходит через травостой и идет на нагрев почвы [10]. Таким образом, регистрируемая радиационная температура является результатом баланса тепловых потоков с учетом процессов внутри листовой массы и отражения от поверхности почвы.

В начале вегетационного периода радиационная температура почвы посева не отличается от температуры парового поля при одинаковом способе обработки. Посев ячменя, так же как и паровое поле, производили при глубинной обработке почвы. В связи с этим наибольшие отличия в значениях температуры проявились 11 июня 2020 г., когда значение NDVI поля ячменя достигло 0.47 (NDVI парового поля 0.18) (рис. 3-5).

$$
-761-
$$


Посев овса производили без обработки почвы (технология №-Till). Поэтому на момент посева на поверхности почвы присутствовало большое количество стерни. Сев овса был выполнен на 12 дней позже посева ячменя. Значения NDVI овса начиная с конца мая значительно ниже значений NDVI ячменя (на 0.24 - 11 июня, 0.19 - 1 июля). Низкое проективное покрытие посева овса определило и более высокие значения измеряемой радиационной температуры. При максимальных значениях NDVI (1 июля) средняя температура овса больше температуры ячменя на $6.3^{\circ} \mathrm{C}$.

Наиболее отличным от посевов зерновых культур объектом исследования являются многолетние травы. Растительность этого вида начинает свой рост и развитие ранней весной с наступлением первых положительных температур. 15 мая значения NDVI составили 0.4, что свидетельствует о наличии значительного количества зеленой фитомассы. При этом температура этого растительного покрова равнялась $6.4{ }^{\circ} \mathrm{C}$ и была минимальной по сравнению с температурой посевов овса и ячменя. На момент проведения исследования всходы на посевах отсутствовали и значения NDVI посевов составляли 0.15 и 0.09. Последующий рост растительности посевов приводит к увеличению сомкнутости полога и уменьшению влияния почв при формировании радиационной температуры. Температура посева многолетних трав имеет более низкие значения по сравнению со значениями температуры посевов ячменя, овса и парового поля (исключение 27 мая). Проведение сенокошения в конце июня привело к снижению объема фитомассы, и вследствие этого к уменьшению значения NDVI и увеличению радиационной температуры.

Анализ измерений радиационной температуры поверхности исследуемых участков 27 мая 2020 г. показал, что выпавшие накануне осадки (25 мая - 3 мм, 26 мая - 4 мм осадков) увлажнили почву. В связи с этим увеличились затраты тепла на испарение с поверхности почвы и ее температура уменьшилась. Наличие растительности на поверхности почвы в посеве ячменя и многолетних трав служит сдерживающим фактором уменьшения температуры деятельного слоя. Температура поверхности пара на 2.8 и $2.6^{\circ} \mathrm{C}$ ниже, чем на поверхности многолетних трав и ячменя. Поверхность посева овса имеет наиболее низкие значения температуры $-3{ }^{\circ} \mathrm{C}$. В данный момент всходы на поле присутствуют единично, доминирующий фактор в формировании температуры - присутствие большого количества стерни.

На стадии повышения температуры (с 27 мая по 1 июля) радиационная температура посевов ячменя и многолетних трав растет медленнее, чем на поверхностях с овсом и на парах. Это говорит о том, что данные посевы являются экранирующими поверхностями. То есть в это время они способствуют сохранению влаги в почве, что считают положительным фактором. Таким образом, появляется возможность по динамике температур судить о сохранности влаги в почве на различных типах растительности и при накоплении статистически значимых данных приходить к ее количественной оценке.

Следует также учитывать различную функциональную нагрузку дневных и ночных измерений радиационной температуры. Дневные измерения могут позволить получение пространственных данных, по которым можно будет оценить состояние растительности и динамику влажности на посевных площадях. Здесь важным методическим приемом может быть дифференцирование различных площадей в одинаковое время съемки. Применение такого подхода абсолютно реально при использовании беспилотных воздушных судов, так как измерения на различных участках проводятся практически синхронно.

$$
-762-
$$




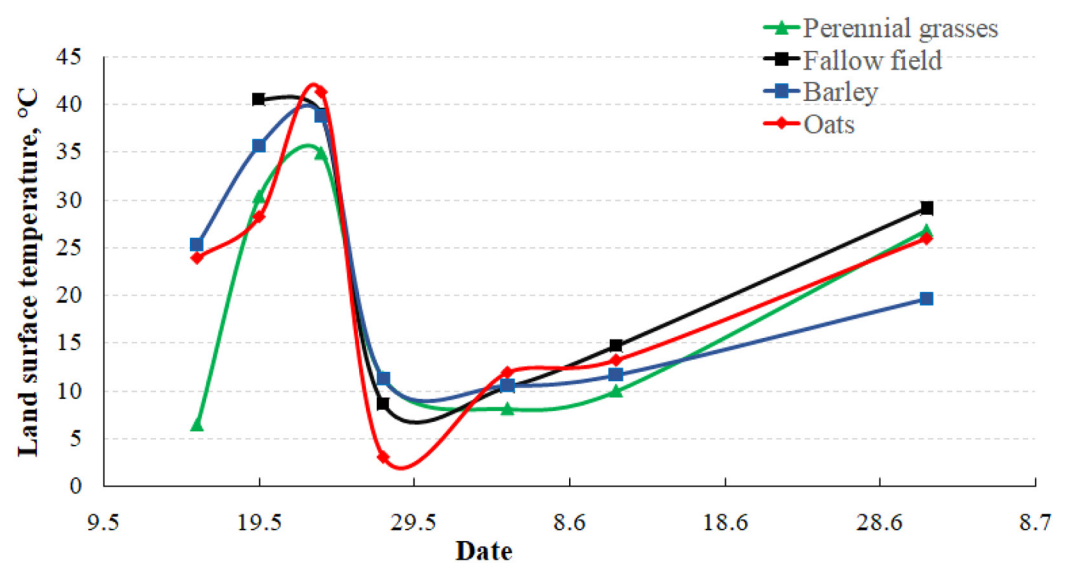

Рис. 3. Средние значения радиационной температуры на исследуемых тестовых участках по данным ZENMUSE XT2

Fig. 3. Average values of land surface temperature in the studied test sites based on ZENMUSE XT2 data

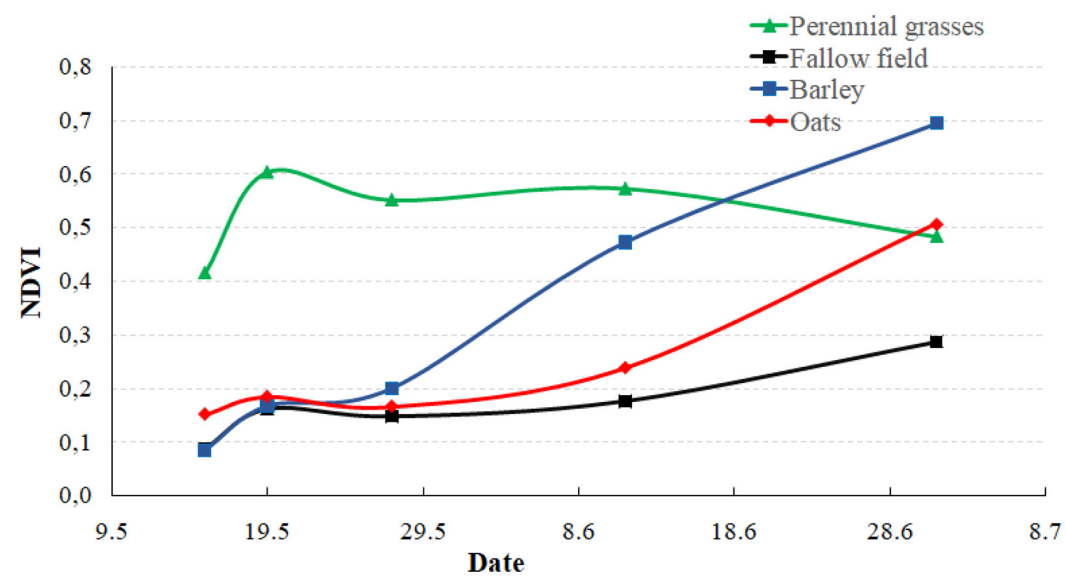

Рис. 4. Средние значения NDVI на исследуемых тестовых участках по данным PlanetScope

Fig. 4. Average NDVI values in the studied test sites based on PlanetScope data

Ночные измерения на посевных площадях планируется провести в ближайшем будущем. Они могут позволить регистрацию базового распределения влажности, связанной с весенним накоплением влаги, высотных микронеоднородностей и динамикой осадков.

На рис. 5 представлены пространственные распределения радиационной температуры на исследуемых тестовых участках с 15 мая по 11 июня 2020 г., позволяющие оценить внутрипольную неоднородность температуры. Такая информация может быть эффективно использована при применении технологий точного земледелия.

\section{Выводы}

Для оценки пространственного и временного распределения радиационной температуры сельскохозяйственных угодий проведено измерение температуры с помощью камеры 


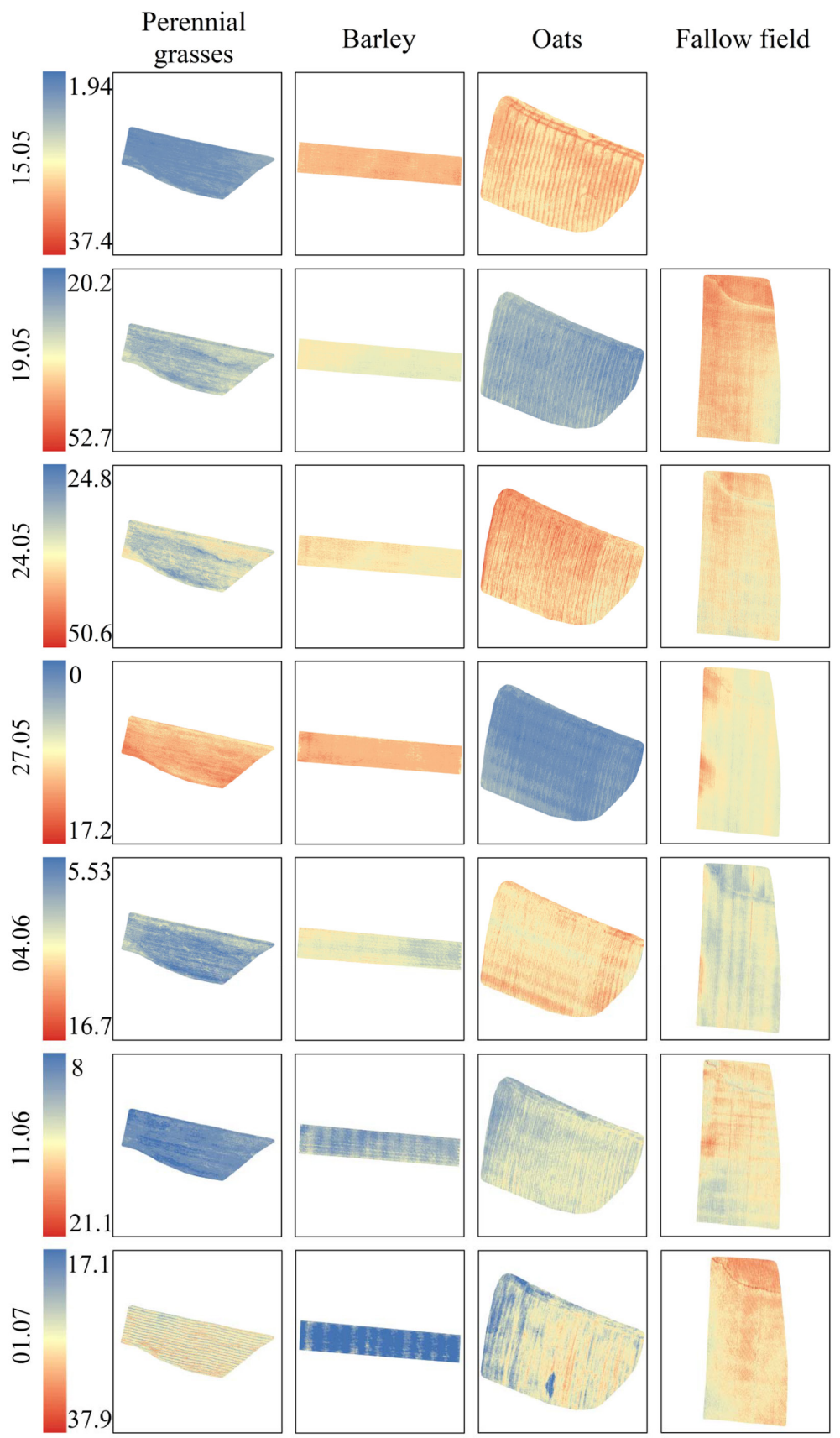

Рис. 5. Пространственное распределение радиационной температуры тестовых участков, съемка выполнена камерой ZENMUSE XT2. Даты съемок 15, 19, 23, 27 мая, 4 и 11 июня, 1 июля 2020 г., пространственное разрешение 12-14 см

Fig. 5. Spatial distribution of the test sites temperature based on ZENMUSE XT2 data. Campaign dates 15.05, $19.05,23.05,27.05,4.06,11.06,01.07 .2020$ (spatial resolution $-12-14 \mathrm{~cm}$ )

ZENMUSE XT2, установленной на БBC DJI Matrice 210 RTK V2. Оценка состояния растительности посевов выполнена по спутниковым данным PlanetScope (NDVI) с пространственным разрешением 3 м. 
Проведенные исследования показали следующее:

- использование съемок БВС позволяет получать данные высокого пространственного разрешения 12-14 см. Данное разрешение дает возможность оценивать внутрипольную неоднородность температуры исследуемых объектов;

- установлено, что присутствие растений и величина их проективного покрытия являются определяющими в формировании температурных условий почвенного покрова. Рост и развитие растительного покрова, его высоты и сомкнутости изменяют условия температурного режима. Деятельной поверхностью становится не почва, а растительный покров;

- применение дифференцированного подхода к измерению температуры в дневное время может стать маркером состояния и типа посевов;

- ночные измерения могут позволить регистрацию базового распределения влажности, связанной с весенним накоплением влаги, высотных микронеоднородностей и динамикой осадков;

- измерение динамики температур может использоваться для оценки влияния растительности различного типа на сохранение влаги в почве.

\section{Список литературы / References}

[1] Sami Khanal, John Fulton, Scott Shearer. An overview of current and potential applications of thermal remote sensing in precision agriculture. Computers and Electronics in Agriculture, 2017, 139, 22-32.

[2] Sepulcre-Canto' G., Zarco-Tejada P.J., Jime'nez-Muñoz J.C., Sobrino J.A., de Miguel E., Villalobos F.J. Detection of water stress in an olive orchard with thermal remote sensing imagery. Agricultural and Forest meteorology, 2006, 136(1-2), 31-44.

[3] Meron M., Tsipris J., Orlov V., Alchanatis V., Cohen Ya. Crop water stress mapping for sitespecific irrigation by thermal imagery and artificial reference surfaces. Precision agriculture, 2010, 11(2), 148-142.

[4] Hamlyn Jones, Ilkka Leinonen. Combining thermal and visible imagery for estimating canopy temperature and identifying plant stress. Journal of Experimental Botany, 2004, 55(401), 1423-1431.

[5] Roselyne Ishimwe, K. Abutaleb, F. Ahmed. Applications of Thermal Imaging in Agriculture - A Review. Advances in Remote Sensing, 2014, 3(3), 128-140.

[6] Anupma Prakash. Thermal remote sensing: concepts, issues and applications. International Archives of Photogrammetry and Remote Sensing, 2000, 33, 239-243.

[7] Martha C. Anderson, Richard G. Allen, Anthony Morse, William P. Kustas. Use of Landsat thermal imagery in monitoring evapotranspiration and managing water resources. Remote Sensing of Environment, 2012, 122, 50-65.

[8] Jordan C.F. Derivation of leaf-area index from quality of light on the forest floor. Ecology, $1969,50,663-666$.

[9] Кронбер П. Дистанционное изучение Земли: Основы и методы дистанционных исследований в геологии, М.: Мир, 1988. 343 с. [Kronber P. Remote sensing of the Earth: Basics and methods of remote sensing in geology, Moscow, Mir, 1988, 343 p. (in Russian)].

[10] Венцкевич Г.3. Сельскохозяйственная метеорология. Л.: Гидрометеоиздат, 1952. 324 с. [Ventskevich G.Z. Agricultural meteorology, Leningrad, 1952, 324 p. (in Russian)] 